\title{
Daily Activities and Sleep Durations of Patients with Ischemic Heart Disease Who Were Discharged to Their Homes after Elective Percutaneous Coronary Intervention
}

\author{
Yuko Yasuhara1, Tetsuya Tanioka', Rozzano Locsin'1, Waraporn Kongsuwan², Beth King ${ }^{3}$, \\ Haruo Kobayashi ${ }^{4}$ \\ ${ }^{1}$ Department of Nursing, Institute of Biomedical Sciences, Tokushima University Graduate School, Tokushima, Japan \\ ${ }^{2}$ Department of Medical Nursing, Faculty of Nursing, Prince of Songkla University, Songkhla, Thailand \\ ${ }^{3}$ Christine E. Lynn College of Nursing, Florida Atlantic University, Boca Raton, FL, USA \\ ${ }^{4}$ Kyushu University of Health and Welfare, Fukuoka, Japan \\ Email: yasuhara@medsci.tokushima-u.ac.jp
}

How to cite this paper: Yasuhara, Y., Tanioka, T., Locsin, R., Kongsuwan, W., King, B. and Kobayashi, H (2017) Daily Activities and Sleep Durations of Patients with Ischemic Heart Disease Who Were Discharged to Their Homes after Elective Percutaneous Coronary Intervention. Open Journal of Psychiatry, 7, 318-328.

https://doi.org/10.4236/ojpsych.2017.74027

Received: August 10, 2017

Accepted: September 11, 2017

Published: September 14, 2017

Copyright $\odot 2017$ by authors and Scientific Research Publishing Inc. This work is licensed under the Creative Commons Attribution International License (CC BY 4.0).

http://creativecommons.org/licenses/by/4.0/

\begin{abstract}
The purpose of this study was to examine the relationship between daily activities and sleep durations for patients following elective percutaneous coronary intervention (ePCI) and diagnosed with ischemic heart disease (IHD) after discharge to their homes. The actigraph data were used to collect data from twenty five patients. The duration of night-time sleep (minutes from the start to end of night-time) and actual night-time sleep duration (total sleep duration excluding wake-up durations of night-time) on the seventh day after discharge were divided into three groups; less than 360,360 to 480 , and more than 480 minutes (short, optimal and long respectively). Subsequently, among the three groups of patients, the data were analyzed by Kruskal Wallis H-test with multiple comparison procedures using the Scheffé-test in order to compare differences in daytime activity items at seven days after discharge from the hospital. Total daytime nap duration $(p<0.05)$, percent nap duration in day time $(p<0.05)$, and longest daytime nap duration $(p<0.05)$ were significantly higher and the daytime activity index which was significantly lower in the group with short night-time sleep durations than those with optimal night-time sleep duration $(p<0.05)$. However, the duration of night-time sleep and daytime activity did not significantly differ. If actual night-time sleep duration is improved from 360 to 480 minutes, daytime nap could potentially be decreased. Determining objective sleep conditions for patients and treating sleep disorders may improve overall patient health, facilitating
\end{abstract}


appropriate sleep and wake rhythms.

\section{Keywords}

Actigraphy, Elective Percutaneous Coronary Intervention,

Actual Night-Time Sleep Duration, Daily Activity

\section{Introduction}

Coronary heart disease (CHD) is one of the leading causes of mortality and morbidity worldwide [1] [2]. The Ministry of Health, Labour and Welfare Ministry of Japan, has identified cardiac disease as the second leading cause of death in Japan. In 2011, 752,000 adults were diagnosed with ischemic heart disease (IHD) [3]. Elective Percutaneous Coronary Intervention (ePCI), which involves coronary angioplasty, is the most widely performed procedure for the treatment of symptomatic coronary disease [4]. Drug-eluting stents for CHD have been associated with reduced target vessel revascularization and an increased survival rate [5]. However, there are several significant factors that have been associated with a decrease in survival rate following ePCI; diets, smoking, physical activities, stress [6] and sleep disorders including obstructive sleep apnea [7] [8].

Several studies have examined the relationship between sleep duration and increased risk of IHD [9] [10]. The Jichi Medical School Cohort Study revealed that the risk of cardiovascular events was higher among men who slept for fewer than 6 hours per day than those who slept from 7 to 7.9 hours per day [11]. In addition, the risk of a myocardial infarction was higher in women who slept less than 6 hours [12]. On the contrary the Japan Collaborative Cohort Study for Evaluation of Cancer Risk found that women who sleep more than 9 hours per day also had a higher risk of IHD [10] or total cardiovascular disease [13].

Similarly, several studies have found that both, short and long durations of sleep are associated with increased mortality in persons with CHD and IHD, and that the relationship is $U$-shaped, with total mortality reaching a lowest point at 7 to 8 hours of sleep [14] [15]. While many studies have suggested that night-time sleep duration is a risk associated with CHD and IHD, however the relationship between restenosis and sleep duration after ePCI has not been fully evaluated.

In order to provide appropriate interventions, it is important to understand factors related to sleep. A review of the literature identified several factors associated with sleep duration and sleep quality; gender [16], age [17], negative affectivity [18], diet [19], daytime nap [20] [21], and activities of daytime [22] [23]. However, no studies could be found which explored actual sleep duration among patients with IHD after ePCI. Little is known about the relationship between daytime activities and night-time sleep durations after the ePCI procedure. 


\section{Purpose of the Study}

The purpose of the study was to determine the relationship between daytime activities and actual night-time sleep duration of patients with IHD following ePCI once discharged from the hospital.

\section{Methods}

\subsection{Subjects and Study Location}

The sample consisted of 25 patients from a public hospital located in southwest Japan. Subjects met the following inclusion criteria: 1) no history of heart failure or life-threatening arrhythmia before ePCI; 2) no diagnosis of chronic mental illness requiring psychotropic medication, 3) no sleep disorders; and 4) ePCI as initial therapy or two or more re-treatments by ePCI.

Data were collected between August 2009 and August 2011. The demographic characteristics of the sample were: male, $\mathrm{N}=14$ (56.0\%); female, $\mathrm{N}=11$ (44.0\%); average age, 65.1 (SD 11.4) years, age range was $47-88$ years; those with multiple ePCI were $\mathrm{N}=19$ (76.0\%), while 6 (24.0\%) were first ePCI.

\subsection{Data Collection Methods}

Actigraphy is a non-invasive technique used to assess sleep-wake cycles using a portable instrument called the Actigraph.

Actigraph data using the sleep/awake formula of Cole and others closely correlate with polysomnography, with reliability coefficients ranging from 0.89 to 0.98 for normal sleep [24] [25] [26]. In this study, a Micro-mini Accelerometer type Actigraph (Ambulatory Monitoring, Inc. Ardsley, NY, USA) was used to measure sleep condition. The actigraph used zero crossing mode: 2 - $3 \mathrm{~Hz}$, a time constant of $0.01 \mathrm{G} / \mathrm{rad} / \mathrm{sec}$ and an epoch of 1 minute. $\mathrm{G}$ is gravitational acceleration $\left(9.8 \mathrm{~m} / \mathrm{sec}^{2}\right)$. The actigraph was attached to each subject's non-dominant arm 1 to 2 days prior to discharge and 6 days after discharge from the hospital, excluding the day of discharge, for a total of seven days. The subjects were instructed to wear the actigraph on their non-dominant wrist except when bathing.

\subsection{Data Analysis}

Actigraphic data were imported from the external interface using an ACT2000/ACT Millennium, displayed and analyzed using Action W-2 (AW2) software (Ambulatory Monitoring) based on a standardized sleep scoring algorithm [24]. Daytime activities were defined as activities during the day, including nap time. Actual night-time was defined as total sleep duration excluding wake-up durations in night-time using AW2. Night-time data used phase between day-time and next day-time which was identified by AW2 software.

Data analysis consisted of seven days of night-time and daytime data. The duration of night-time sleep (minutes from the start to end of night-time) and actual night-time sleep duration were divided three sleep durations groups: less 
than 360 minutes, 360 to 480 minutes, and more than 480 minutes (short, optimal and long respectively) [27].

Samples are small, therefore this study used appropriate nonparametric tests like as the Kruskal Wallis $\mathrm{H}$-test with multiple comparison procedures using the Scheffé-test. Comparisons were made between subjects with multiple ePCI ( $=$ 19) and subjects with first ePCI $(\mathrm{N}=6)$ using Mann-Whitney U-test. All data were analyzed using IBM SPSS ver. 19.0 and Excel statistical functions ver. 2006 (SSRI: Social Survey Research Information, for windows). The level of significance was set at $p<0.05$.

\subsection{Ethical Considerations}

This research study was approved by the Ethics Committee of Tokushima Prefectural Hospital (No 09-07) and the Tokushima University Hospital Ethics Board (No. 1257). Consent was also obtained from the University Hospital Medical Information Network Clinical Trial Registration (UMIN-CTR, No R000012184). Subjects were assured that their personal information would be protected, and the results of the study would only be reported as aggregate data, and used only for research purposes. The purpose and procedure of the study were explained to all subjects and informed consent was obtained from the subjects.

\section{Results}

Table 1 shows the differences in daytime activity with durations of night-time sleep at seven days after discharge among the three groups of subjects.

Results of actual night-time sleep duration, total daytime nap duration $(p<$ $0.01)$, percent nap duration in the daytime $(p<0.01)$, longest daytime nap duration $(p<0.05)$ and daytime activity index $(p<0.05)$ significantly differed.

However, mean daytime activities compared with actual night-time sleep duration did not show significant difference.

The duration of night-time sleep, total daytime nap duration, percent nap duration in the daytime, longest daytime nap duration, daytime activity index and mean daytime activities did not significantly differ among the three groups of patients.

In actual night-time sleep duration, multiple comparisons also showed that total daytime nap durations were significantly longer in the group with short night-time sleep duration, than with optimal night-time sleep durations (121.0 $\min$ vs. $15.0 \mathrm{~min} ; p<0.05)$. The percent nap duration in the daytime was significantly higher in the group with shorter than with optimal night-time sleep durations $(12.6 \%$ vs. $1.5 \% ; p<0.05)$. The longest daytime nap duration was significantly longer ( $35.0 \mathrm{~min}$ vs. $7.0 \mathrm{~min} ; p<0.05)$ and the daytime activity index was significantly lower in the group with shorter, than optimal night-time sleep duration (89.5\% vs. $96.2 \%$; $p<0.05)$.

Table 2 shows the difference between subjects with multiple ePCI $(\mathrm{N}=19)$ 
Table 1. Differences in daytime activity with durations of night-time sleep at seven days after discharge among the night-time sleep length (short, optimal and long).

\begin{tabular}{|c|c|c|c|c|c|c|c|c|c|c|c|}
\hline \multirow{4}{*}{ Items } & \multicolumn{5}{|c|}{ Duration of night-time sleep $(\mathrm{min}) \mathrm{N}=25$} & \multicolumn{6}{|c|}{ Actual night-time sleep duration $(\mathrm{min}) \mathrm{N}=25$} \\
\hline & & Optimal & Long & & & Shoort & Optimal & Long & & & \\
\hline & 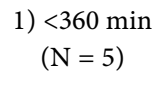 & 2) $\begin{array}{c}360-480 \mathrm{~min} \\
(\mathrm{~N}=7)\end{array}$ & $\begin{array}{l}\text { 3) }>480 \mathrm{~min} \\
(\mathrm{~N}=13)\end{array}$ & $x^{2}$ & $\begin{array}{c}p \\
\text { value }\end{array}$ & 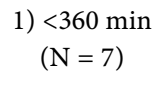 & $\begin{array}{c}\text { 2) } 360-480 \mathrm{~min} \\
(\mathrm{~N}=13)\end{array}$ & $\begin{array}{l}\text { 3) }>480 \mathrm{~min} \\
(\mathrm{~N}=5)\end{array}$ & $x^{2}$ & $\begin{array}{c}p \\
\text { value }\end{array}$ & $\begin{array}{l}\text { Multiple } \\
\text { comarison }\end{array}$ \\
\hline & Median & Median & Median & & & Median & Median & Median & & & \\
\hline $\begin{array}{l}\text { Total daytime } \\
\text { nap duration } \\
(\min )\end{array}$ & 99.0 & 54.0 & 37.0 & 2.3 & 0.31 & 121.0 & 15.0 & 69.0 & 10.1 & 0.01 & $\begin{array}{c}1)>2) \\
\chi^{2}=8.2, \\
p=0.016\end{array}$ \\
\hline $\begin{array}{l}\text { Percent nap } \\
\text { duration in the } \\
\text { daytime }(\%)\end{array}$ & 9.5 & 5.3 & 3.9 & 2.0 & 0.37 & 12.6 & 1.5 & 8.4 & 9.6 & 0.01 & $\begin{array}{c}1)>2) \\
\chi^{2}=7.4 \\
p=0.025\end{array}$ \\
\hline $\begin{array}{l}\text { Longest daytime } \\
\text { nap duration } \\
(\mathrm{min})\end{array}$ & 35.0 & 31.0 & 17.0 & 4.0 & 0.13 & 35.0 & 7.0 & 28.0 & 8.0 & 0.02 & $\begin{array}{c}1)>2) \\
\chi^{2}=7.1 \\
p=0.028\end{array}$ \\
\hline $\begin{array}{l}\text { Daytime activity } \\
\text { Index (\%) }\end{array}$ & 90.0 & 94.5 & 95.8 & 1.9 & 0.38 & 89.5 & 96.2 & 87.5 & 7.5 & 0.02 & $\begin{array}{c}1)<2) \\
\chi^{2}=6.4 \\
p=0.042\end{array}$ \\
\hline $\begin{array}{l}\text { Mean daytime } \\
\text { activity index } \\
\text { (count/min) }\end{array}$ & 181.7 & 168.0 & 192.0 & 4.0 & 0.14 & 159.5 & 200.6 & 188.7 & 4.7 & 0.09 & \\
\hline
\end{tabular}

Kruskal Wallis H-test with multiple comparison procedures using Scheffé-test. Duration of night-time sleep is from the start to end of sleep duration at night-time. Actual night-time sleep duration is total sleep duration excluding wake-up duration at night-time. Daytime activity index which is the percent epochs with $>0$ activity score for day time duration. Also, one epoch means same as one minute.

Table 2. Difference between subjects with multiple ePCI $(\mathrm{N}=19)$ and subjects with first ePCI $(\mathrm{N}=6)$.

\begin{tabular}{|c|c|c|c|c|}
\hline \multirow{2}{*}{ Item } & Subjects with multiple ePCI $(\mathrm{N}=19)$ & Subjects with first ePCI $(\mathrm{N}=6)$ & \multirow{2}{*}{$\mathrm{Z}$} & \multirow{2}{*}{$p$ value } \\
\hline & Median & Median & & \\
\hline Duration of night-time sleep (min) & 450.00 & 485.00 & -1.08 & 0.28 \\
\hline Actual night-time sleep duration (min) & 402.00 & 449.50 & -1.21 & 0.23 \\
\hline Total daytime nap duration (min) & 54.00 & 22.50 & -1.31 & 0.19 \\
\hline Percent nap duration in the daytime (\%) & 5.32 & 2.35 & -1.24 & 0.22 \\
\hline Longest daytime nap duration (min) & 28.00 & 12.50 & -1.50 & 0.14 \\
\hline Daytime activity Index (\%) & 91.34 & 97.63 & -2.10 & 0.04 \\
\hline Mean daytime activity index (count/min) & 188.74 & 206.30 & -1.21 & 0.23 \\
\hline
\end{tabular}

Mann-Whitney U-test. Duration of night-time sleep is from the start to end of sleep duration at night-time. Actual night-time sleep duration is total sleep duration excluding wake-up duration at night-time. Daytime activity index which is the percent epochs with $>0$ activity score for day time duration. Also, one epoch means same as one minute.

and subjects with first ePCI $(\mathrm{N}=6)$. There was a significant difference in daytime activity index (\%) $(91.34 \%$ vs. $97.63 \% ; p<0.05)$. However, other items did not show significant differences.

\section{Discussion}

Night-time sleep might influence daytime activity and nap duration. Total daytime nap duration, percent nap duration in the daytime and longest daytime nap 
duration significantly differed when compared with actual night-time sleep duration. First, in actual night-time sleep duration, total daytime nap duration, percent nap duration and longest daytime nap duration were significantly longer in the group with shorter night-time sleep than with optimal sleep duration. If total daytime nap duration and longest daytime nap durations are longer, total night-time sleep duration might be shorter. These findings suggest that daytime nap duration may be a factor that leads to poor night-time sleep quality.

Suzuki [10] found that the relative risk of IHD is 1.23-fold and 1.42-fold higher for men and for women who took a nap, respectively. On the other hand, when controlling for sex as well as the indicated potential confounders and using those not taking midday sleep as a reference category, both men and women taking midday nap of any frequency or duration had a coronary mortality risk of 0.66 (95\% confidence interval, 0.45 - 0.97) [28]. However, the relationship between total daytime nap durations and risk of IHD needs further study.

Short sleep durations confer increased risk of developing a risk of IHD [11] [12], and the relative risk of sleep duration and IHD is a horseshoe curve [14] [15]. Therefore, if night-time sleep duration can be improved from short to optimal, daytime naps could potentially become shorter. In addition, optimal sleep duration might lower the risk for incident IHD, and be a contributory factor in reducing the risk of cardiovascular disease.

A longer duration of night-time sleep might not influence daytime activity. Although the mechanisms underlying this association are not clear [9] longer sleep durations are associated with mortality from several causes [29] [30]. These findings suggested an association between daytime activity and night-time sleep conditions. The daytime activity index was significantly lower in the group with shorter, than optimal night-time sleep duration of after discharge. However, no significant differences were obtained in daytime parameters among those with long sleep duration according to actual night-time sleep in this study.

Patients with IHD can develop anxiety due to coronary artery restenosis [31] [32]. Therefore, such patients' physical activity and activities of daily living (ADL) might are limited.

In this study, it was confirmed significant lower daytime activity index (\%) in subjects with multiple ePCI than first ePCI.

The majority of patients with acute coronary syndrome are elderly, dependency in activities of daily living is as one of prognostic predictors [33]. About half of our study subjects were more than 70's years old. Patients might have anxiety to have multiple ePCI, these psychological issues may significantly affect a patient's coronary cardiac rehabilitation (CCR) programs.

The CCR is aimed at improving exercise capacity and optimizing daily physical functioning in relation to individual physical activity limitations and participation restrictions. Also, these programs provide inactive patients to develop and maintain an active lifestyle [34]. The CCR has been shown to reduce allcause mortality, cardiovascular mortality and events after acute myocardial infarction [35]. Therefore, daytime activities should be maintained at levels that 
are sufficient to avoid poor sleep quality in patients who have not received CCR after PCI.

On the other hand, in this study, the duration of night-time sleep did not significantly affect daytime activity and sleep durations. The duration of night-time sleep was spent in bed. Most patients with IHD are elderly and non-REM sleep decreases whereas arousal increases in the elderly regardless of sleep duration [36]. The amount of time spent asleep in bed might not be identical to actual night-time sleep duration.

More active daily activities might lead to reducing daytime napping and optimal night-time sleep.

In that sense, CCR might be important for patients with IHD [37] [38]. Hence, information should be provided about CCR or appropriate daytime activity levels for patients, and ADL should be promoted so that actual sleep duration (except arousal during sleep) becomes optimal. Our finding was the total sleep time is important to patients.

However, the limitations of this study include small sample size, possible selection bias, and the patient's sleeping patterns and conditions were not measured before ePCI.

\section{Conclusions}

Total daytime nap duration and longest daytime nap duration were significantly longer, percent nap duration in the day time (ratio of nap duration between the daytime) was significantly higher in the group with short night-time sleep durations than those with optimal night-time sleep duration. In addition, the daytime activity index was significantly lower in the group with shorter sleep durations than those with optimal sleep durations.

The data from this study can also be used to assist patients with IHD to anticipate changes in sleep patterns during recovery and to appreciate the subjective situation of the patient after ePCI. Clarifying objective sleep conditions for patients and treating sleep disorders might improve the health of persons with IHD.

\section{Acknowledgements}

The authors would like to thank subject patients and all staff members of the hospital who have helped this research. And we also would like to express our deep gratitude to the academic supervisors.

\section{Competing Interests}

The authors declare that they have no competing interests.

\section{Author's Contributions}

$\mathrm{YY}$ is responsible for the idea behind this study and its structure. RL, WK, \& BK evaluation of the data and statistical analysis, and discussion. TT \& $\mathrm{KH}$ are 
responsible for the introduction, discussion part, and its structure. All authors developed the preparation of the manuscript.

\section{Funding}

The authors report no conflicts of interest in this work.

\section{References}

[1] Kaneez, F., Mohammad, Y., Mehreen, Ai., Faizan, I.B., Muhammad, S.K., Akash, K., Neelam, K., Muhammad, N.L., Mohammad, H.A., Raamish, B.A., Hoshang, R.K., Qaiser, Zaidi, H., Smeen, K.M. and Bahram, K. (2016) Comparison of the Postprocedural Quality of Life between Coronary Artery Bypass Graft Surgery and Percutaneous Coronary Intervention: A Systematic Review. Cardiology Research and Practice, 2016, Article ID: 7842514. https://doi.org/10.1155/2016/7842514

[2] Townsend, N., Wickramasinghe, K., Bhatnagar, P., Smolina, K., Nichols, M., Leal, J., Luengo-Fernandez, L. and Rayner, M. (2012) Coronary Heart Disease Statistics 2012. British Heart FoundationGreater London House, London. https://www.bhf.org.uk/publications/statistics/coronary-heart-disease-statistics-2012

[3] Incorporated Administrative Agency National Statistics Center (2011) Ministry of Health, Labour and Welfare, Portal Site of Official Statistics of Japan. (In Japanese) http://www.e-stat.go.jp/SG1/estat/GL08020103.do?_toGL08020103_\&listID=000001 $103073 \&$ disp $=$ Other\&requestSender $=$ dsearch

[4] Serruys, P.W., Jaegere, P., Kiemeneij, F., Macaya, C., Rutsch, W., Heyndrickx, G., Emanuelsson, H., Marco, J., Legrand, V., Materne, P., Belardi, J., Sigwart, U., Colombo, A., Goy, J.J., Heuvel, P., Delcan, J. and Morel, M., Benestent Study Group (1994) A Comparison of Balloon-Expandable-Stent Implantation with Balloon Angioplasty in Patients with Coronary Artery Disease. The New England Journal of Medicine, 331, 489-495. https://doi.org/10.1056/NEJM199408253310801

[5] American College of Emergency Physicians.; Society for Cardiovascular Angiography and Interventions., O'Gara, P.T., Kushner, F.G., Ascheim, D.D., Casey, D.E. Jr, Chung, M.K., de Lemos J.A., Ettinger, S.M., Fang, J.C., Fesmire, F.M., Franklin, B.A., Granger ,C.B., Krumholz, H.M., Linderbaum, J.A., Morrow, D.A., Newby, L.K., Ornato, J.P., Ou, N., Radford, M.J., Tamis-Holland, J.E., Tommaso, C.L., Tracy, C.M., Woo, Y.J., Zhao, D.X., Anderson, J.L., Jacobs, A.K., Halperin, J.L., Albert, N.M., Brindis, R.G., Creager, M.A., DeMets, D., Guyton, R.A., Hochman, J.S., Kovacs, R.J., Kushner, F.G., Ohman, E.M., Stevenson, W.G. and Yancy, C.W. (2013) 2013 ACCF/AHA Guideline for the Management of ST-Elevation Myocardial Infarction: A Report of the American College of Cardiology Foundation/American Heart Association Task Force on Practice Guidelines. Journal of the American College of Cardiology, 61, 485-510.

[6] Lisspers, J., Sundin, O., Ohman, A., Hofman-Bang, C., Rydén, L. and Nygren, A. (2005) Long-Term Effects of Lifestyle Behavior Change in Coronary Artery Disease: Effects on Recurrent Coronary Events After Percutaneous Coronary Intervention. Health Psychology, 24, 41-48. https://doi.org/10.1037/0278-6133.24.1.41

[7] Wu, X., Lv, S., Yu, X., Yao, L., Mokhlesi, B. and Wei, Y. (2015) Treatment of OSA Reduces the Risk of Repeat Revascularization after Percutaneous Coronary Intervention. Chest, 147, 708-718. https://doi.org/10.1378/chest.14-1634

[8] Steiner, S., Schueller, P.O., Hennersdorf, M.G., Behrendt, D. and Strauer, B.E. (2008) Impact of Obstructive Sleep Apnea on the Occurrence of Restenosis after Elective Percutaneous Coronary Intervention in Ischemic Heart Disease. Respiratory Research, 9, 50. https://doi.org/10.1186/1465-9921-9-50 
[9] Kripke, D.F., Garfinkel, L., Wingard, D.L., Klauber, M.R. and Marler, M.R. (2002) Mortality Associated with Sleep Duration and Insomnia. Archives of General Psychiatry, 59, 131-136. https://doi.org/10.1001/archpsyc.59.2.131

[10] Suzuki, K. (2007) Health Conditions and Mortality in Japan Collaborative Cohort Study for Evaluation of Cancer (JACC). Asian Pacific Journal of Cancer Prevention, 8, 25-34. http://journal.waocp.org/article_24675_df404e5f378df9d2d829bf2510869a04.pdf

[11] Amagi, Y., Ishikawa, S., Gotoh, T., Kayaba, K., Nakamura, Y. and Kajii, E. (2004) Sleep Duration and Mortality in Japan: The Jichti Medical School Cohort Study. Journal of Epidemiology, 14, 124-128. https://doi.org/10.2188/jea.14.124

[12] Amagai, Y., Ishikawa, S., Gotoh, T., Kayaba, K., Nakamura, Y. and Kajii, E. (2010) Sleep Duration and Incidence of Cardiovasucular Event in a Japanese Population. The Jichi Medical Study Cohort Study. Journal of Epidemiology, 20, 106-110. https://doi.org/10.2188/jea.JE20090053

[13] Ikehara, S., Iso, H., Date, C., Kikuchi, S., Watanabe, Y., Wada, Y., Inaba, Y. and Tamakoshi, A., JACC Study Group (2009) Association of Sleep Duration with Mortality from Cardiovascular Disease and Other Causes for Japanese Men and Women: The JACC Study. Sleep, 32, 295-301.

https://www.ncbi.nlm.nih.gov/pmc/articles/PMC2647783/ https://doi.org/10.1093/sleep/32.3.295

[14] Sabanayagam, C. and Shankar, A. (2010) Sleep Duration and Cardiovascular Disease: Results from the National Health Interview Survey. Sleep, 33, 1037-1042.

https://www.ncbi.nlm.nih.gov/pmc/articles/PMC2910533/ https://doi.org/10.1093/sleep/33.8.1037

[15] Ayas, N.T., White, D.P., Manson, J.E., Stampfer, M.J., Speizer, F.E., Malhotra, A. and Hu, F.B. (2003) A Prospective Study of Sleep Duration and Coronary Heart Disease in Women. Archives of Internal Medicine, 163, 205-209.

https://doi.org/10.1001/archinte.163.2.205

[16] Tatone-Tokuda, F., Dubois, L., Ramsay, T., Girard, M., Touchette, E., Petit, D. and Montplaisir, J.Y. (2012) Sex Differences in the Association Between Sleep Duration, Diet and Body Mass Index: A Birth Cohort Study. Journal of Sleep Research, 21, 448-460. https://doi.org/10.1111/j.1365-2869.2011.00989.x

[17] Auyeung, T.W., Lee, J.S., Leung, J., Kwok, T., Leung, P.C., Woo, J. and Wing, Y.K. (2013) Cognitive Deficit Is Associated with Phase Advance of Sleep-Wake Rhythm, Daily Napping, and Prolonged Sleep Duration-A Cross-Sectional Study in 2,947 Community-Dwelling Older Adults. Age (Dordr), 35, 479-486. https://doi.org/10.1007/s11357-011-9366-6

[18] Saeki, U., Nasermoaddeli, A., Sekine, M. and Kagamimori, S. (2008) Relationships of Positive and Negative Affectivity to Sleep Quality in Japanese Civil Servants: 3-Year Follow-Up Study. Sangyo Eiseigaku Zasshi, 50, 219-225. (In Japanese) https://doi.org/10.1539/sangyoeisei.B8002

[19] Dashti, H.S., Scheer, F.A., Jacques, P.F., Lamon-Fava, S. and Ordovás, J.M. (2015) Short Sleep Duration and Dietary Intake: Epidemiologic Evidence, Mechanisms, and Health Implications. Advances in Nutrition, 6, 648-659. https://doi.org/10.3945/an.115.008623

[20] Jung, K.I., Song, C.H., Ancoli-Israel, S. and Barrett-Connor, E. (2013) Gender Differences in Nighttime Sleep and Daytime Napping as Predictors of Mortality in Older Adults: The Rancho Bernardo Study. Sleep Medicine, 14, 12-19. https://doi.org/10.1016/j.sleep.2012.06.004 
[21] Nakagawa, M., Ohta, H., Nagaoki, Y., Shimabukuro, R., Asaka, Y., Takahashi, N., Nakazawa, T., Kaneshi, Y., Morioka, K., Oishi, Y., Azami, Y., Ikeuchi, M., Takahashi, M., Hirata, M., Ozawa, M., Cho, K., Kusakawa, I. and Yoda, H. (2016) Daytime Nap Controls Toddlers' Nighttime Sleep. Scientific Reports, 6, 27246. https://doi.org/10.1038/srep27246

[22] Lambiase, M.J., Gabriel, K.P., Kuller, L.H. and Matthews, K.A. (2013) Temporal Relationships between Physical Activity and Sleep in Older Women. Medicine \& Science in Sports \& Exercise, 45, 2362-2368. https://doi.org/10.1249/MSS.0b013e31829e4cea

[23] McClain, J.J., Lewin, D.S., Laposky, A.D., Kahle, L. and Berrigan, D. (2014) Associations between Physical Activity, Sedentary Time, Sleep Duration and Daytime Sleepiness in US Adults. Preventive Medicine, 66, 68-73. https://doi.org/10.1016/j.ypmed.2014.06.003

[24] Cole, R.J., Kripke, D.F., Gruen, W., Mullaney, D.J. and Gillin, J.C. (1992) Technical Note, Automatic Sleep/Wake Identification from Wrist Activity. Sleep, 15, 461-469. https://doi.org/10.1093/sleep/15.5.461

[25] Shinkoda, H., Matsumoto, K., Hamasaki, J., Seo, Y.J., Park, Y.M. and Park, K.P. (1998) Evaluation of Human Activities and Sleep-Wake Identification Using Wrist Actigraphy. Psychiatry and Clinical Neurosciences, 52, 157-159. https://doi.org/10.1111/j.1440-1819.1998.tb01004.x

[26] Ancoli-Israel, S., Cole, R., Alessi, C., Chambers, M., Moorcroft, W. and Pollak, C.P. (2003) The Role of Actigraphy in the Study of Sleep and Circadian Rhythms. Sleep, 26, 342-392.

http://www.aasmnet.org/Resources/PracticeReviews/cpr_Actigraphy.pdf https://doi.org/10.1093/sleep/26.3.342

[27] Garde, A.H., Hansen, Å.M., Holtermann, A., Gyntelberg, F. and Suadicani, P. (2013) Sleep Duration and Ischemic Heart Disease and All-Cause Mortality: Prospective Cohort Study on Effects of Tranquilizers/Hypnotics and Perceived Stress. Scandinavian Journal of Work, Environment \& Health, 39, 550-558. https://doi.org/10.5271/sjweh.3372

[28] Naska, A., Oikonomou, E., Trichopoulou, A., Psaltopoulou, T. and Trichopoulos, D. (2007) Siesta in Healthy Adults and Coronary Mortality in the General Population. Archives of Internal Medicine, 167, 296-301. https://doi.org/10.1001/archinte.167.3.296

[29] Youngstedt, S.D. and Kripke, D.F. (2004) Long Sleep and Mortality: Rationale for Sleep Restriction. Sleep, 8, 159-174. https://doi.org/10.1016/j.smrv.2003.10.002

[30] Tomakoshi, A. and Ohno, Y., JACC Study Group (2004) Self-Reported Sleep Duration as Predictor of All-Cause Mortality; Results from the JACC Study, Japan. Sleep, 27, 51-54. http://www.journalsleep.org/articles/270105.pdf

[31] Yasuhara, Y., Harano, K., Fujikawa, E., Fujinaga, H., Tanioka, T., Kobayashi, H., Pfaff, G. and Suragarn, U. (2011) Effectiveness of the Integration of Different Types of Quantitative and Qualitative Assessment Indicators for the Patients with Ischemic Heart Disease Who Underwent Percutaneous Coronary Intervention (PCI). Proceeding of the 7 th International Conference on Natural Language Processing and Knowledge Engineering, Tokushima, 454-458.

[32] Yasuhara, Y., Takada, S., Tanioka, T., Kawanishi, C. and Locsin, R.C. (2010) Illness Experiences of Patients with Ischemic Heart Disease during Their Transitional Phase from Hospitalization to Discharge in Japan. The Journal of Medical Investigation, 57, 293-304. https://doi.org/10.2152/jmi.57.293 
[33] Barywani, S.B., Lindh, M., Ekelund, J., Petzold, M., Albertsson, P., Schaufelberger, M., Lund, L. and Fu, M.L.X. (2014) Predictors of Long-Term Outcome of Percutaneous Coronary Intervention in Octogenarians with Acute Coronary Syndrome. IJC Heart \& Vessels, 4, 138-144. https://doi.org/10.1016/j.ijchv.2014.05.004

[34] Achttien, R.J., Staal, J.B., van der Voort, S., Kemps, H.M.C., Koers, H. and Jongert, M.W.A., on behalf of the Practice Recommendations Development Group (2013) Exercise-Based Cardiac Rehabilitation in Patients with Coronary Heart Disease: A Practice Guideline. Netherlands Heart Journal, 21, 429-438.

https://doi.org/10.1007/s12471-013-0467-y

[35] Venturini, E. and Testa, R. (2014) Cardiac Rehabilitation and Percutaneous Coronary Intervention: Together Against Global Burden of Cardiovascular Disease. Journal of Cardiology and Therapy, 1, 3-11. http://www.ghrnet.org/index.php/jct/article/view/599

[36] Okawa, M. (2010) Epidemiology of a Sleep Characteristic and the Sleep Disorder of the Elderly. Geriatric Medical, 48, 729-734. (In Japanese)

http://mol.medicalonline.jp/library/journal/download?GoodsID=ai5gemdd/2010/00 4806/002\&name $=0729-0734$ j\&UserID $=150.59 .64 .134$

[37] Choo, J., Burke, L.E. and Hong, K.P. (2007) Improved Quality of Life with Cardiac Rehabilitation for Post-Myocardial Infarction Patients in Korea. European Journal of Cardiovascular Nursing, 6, 166-171. https://doi.org/10.1016/J.EJCNURSE.2006.07.004

[38] Suzuki, S., Takaki, H., Yasumura, Y., Sakuragi, S., Takagi, S., Tsutsumi, Y., Aihara, N., Sakamaki, F. and Goto, Y. (2005) Assessment of Quality of Life with 5 Different Scales in Patients Participating in Comprehensive Cardiac Rehabilitation after Acute Myocardial Infarction. Circulation Journal, 69, 1527-1534.

https://doi.org/10.1253/circj.69.1527 